https://helda.helsinki.fi

Fiscal Multipliers in a Structural VEC Model with Mixed Normal Errors

Puonti, Päivi Johanna

2016

Puonti , P J 2016 , ' Fiscal Multipliers in a Structural VEC Model with Mixed Normal Errors ' , Journal of Macroeconomics, vol. 48 , pp. 144-154 . https://doi.org/10.1016/j.jmacro.2016.03.003

http://hdl.handle.net/10138/335748

https://doi.org/10.1016/j.jmacro.2016.03.003

cc_by_nc_nd

acceptedVersion

Downloaded from Helda, University of Helsinki institutional repository.

This is an electronic reprint of the original article.

This reprint may differ from the original in pagination and typographic detail.

Please cite the original version. 


\title{
Fiscal Multipliers in a Structural VEC Model with Mixed Normal Errors
}

\author{
Päivi Puonti
}

\begin{abstract}
This paper estimates the effects of fiscal policy shocks on GDP in the United States with a vector error correction (VEC) model in which shocks are identified by exploiting the non-normal distribution of the model residuals. Unlike previous research, the model used here takes into account cointegation between the variables, and applies a data driven method to identify fiscal policy shocks. The approach also allows statistical testing of previous identification strategies, which may help discriminate between them and hence also explain differences between various fiscal multiplier estimates. Our results show that a deficit financed government spending shock has a weak negative effect on output, whereas a tax increase to finance government spending has a positive impact on GDP.
\end{abstract}

Keywords: Fiscal policy, Vector error correction model, Identification

\section{Introduction}

After the recent financial crisis many central banks have had to come to terms with the limits of conventional monetary policy. Because of the zero lower bound on one hand and the prolongation of the economic downturn on the other, policymakers and economists alike have again turned their attention to fiscal policy. Common monetary policy, which is not necessarily optimal from the point of view of any one member country, emphasizes the role of fiscal policy in the euro area. 
Compared to monetary policy, fiscal policy has been viewed as a less agile policy instrument mainly because of implementation lags, but also because of its multi-faceted nature. Fiscal policy consists of the allocation of government expenditure between different categories of consumption and investment as well as decisions about its finance with a particular tax-debt mix. These political decisions are taken at different levels of government administration (e.g. federal, state, provincial, or municipal). Unlike monetary policy, the stance of which can be summarized by an interest rate announced by the central bank, fiscal policy regime cannot be described by a single variable.

Nonetheless, there has been an upsurge of academic research in the macroeconomic effects of government expenditure and tax changes in recent years. Broadly speaking, the key question of interest is whether government spending can stimulate the economy, and what the size (and sign!) of this fiscal or government spending multiplier is. Ramey (2011a) provides a review of both theoretical and empirical research on the government spending multiplier. Theoretically defined multipliers provide a wide range of values depending on the type of model used, the assumptions about the behavior of monetary policy, the type and persistence of government spending, and how it is financed (Ramey 2011a). Consequently, the size of the multiplier is first and foremost an empirical issue.

Given the variety of theoretical and empirical results, many researchers have recently asked whether the multiplier depends on the state of the economy, i.e. whether government fiscal stimulus is more effective when it is used to supplement scant private demand in an economic downturn than in an upturn (Auerbach \& Gorodnichenko 2012, Caggiano et al. 2015). Interestingly, Caggiano et al. (2015) show that this is indeed the case with deep recessions and extreme economic peaks in the US, while no statistically significant differences between normal times, i.e. normal economic downturns and upturns are found. Owyang et al. (2013), and Ramey and Zubairy (2014) also find no evidence of larger fiscal multipliers during downturns. This means that research based on linear models is informative about 
the effectiveness of the fiscal policy instrument in normal times. Given the relative rarity of events like the recent Great Recession, ${ }^{1}$ knowledge about the effectiveness of fiscal stimulus during an ordinary business cycle is admittedly valuable. This paper thus focuses on linear models. ${ }^{2}$

Vector autoregressive (VAR) models seem to have become the main econometric tool for determining the macroeconomic effects of both monetary and fiscal policy (Ramey 2011a, Caldara \& Kamps 2008). Both strands of the empirical literature need to tackle the inherent shock identification problem. Fiscal policy research has relied on four identification strategies: 1) the recursive approach of Sims (1980) applied to fiscal policy by e.g. Auerbach and Gorodnichenko (2012), 2) the frequently applied structural VAR proposed by Blancard and Perotti (2002), 3) the sign restrictions developed by Uhlig (2005) and applied by Mountford and Uhlig (2009) and 4) the narrative approach introduced by Ramey and Shapiro (1998), which exploits unexpected increases in military spending.

Studies using different VAR model specifications and identification schemes have come to diverging conclusions about the size and sometimes even the sign of the multiplier. Unlike with monetary policy, the fifth available strategy,statistical identification methods, has not yet been applied to the study of fiscal policy. Statistical methods that yield additional data based information may be helpful in shock identification, and/or possibly help choose the most suitable among the proposed identification strategies.

This paper thus applies the statistical method introduced by Lanne and Lütke-

\footnotetext{
${ }^{1}$ In the 32-year period studied by Caggiano et al. (2015), they identified two deep recessions in the U.S., whereas according to the NBER Recession Indicator the total number of recessions amounted to five.

${ }^{2}$ As noted by a referee, the inclusion of the Great Recession in the small sample considered may lead to a distorted picture of the effects of government spending shocks in normal times. However, excluding the financial crisis from the sample would significantly reduce the sample size, leading to less accurate estimates and poorer identification. Moreover, from the point of view of nonlinearities, the Great Recession is not a unique event since another such recession was identified by Caggiano et al. (2015) in the sample.
} 
pohl (2010), in which the non-normality of the errors is exploited to identify the structural shocks. More precisely, the errors are assumed to follow a mixture of two normal distributions. The identification strategy of Lanne and Lütkepohl (2010) allows not only identification of the statistical model without any identifying restrictions, but also statistically testing of whether any of the previously used identification strategies are compatible with the properties of the data. If statistical identification of shocks (see Section 3) is obtained following Lanne and Lütkepohl (2010), then the restrictions on the contemporaneous relationships between the variables imposed in the previous identification schemes can be statistically tested. This may also be helpful in labeling the statistically identified shocks, which is always based on outside information (Lanne et al. 2015, Lütkepohl \& Netšunajev 2014). Although additional information is needed to interpret the shocks identified, being able to test their compatibility with the data is an advantage over traditional approaches. Obtaining results that are not dependent on the identification strategy chosen may be seen as a robustness check of previous empirical research.

Unlike any of the previous studies using VARs - linear and non-linear - the vector error correction (VEC) model used in this paper also takes into account the cointegration properties of the variables. The usual practice in the literature is to include the log levels of variables such as GDP, government spending and taxes (Ramey \& Zubairy 2014), even though they are likely to contain a unit root. Phillips (1998) demonstrates that impulse responses are not consistently estimated in structural VARs (SVARs) with variables in levels in the case of unit roots, whereas the VEC specification significantly improves them even for short horizons when the cointegration relations are either known or consistently estimated. Phillips (1998) points out that differing treatments of nonstationarity in models such as unrestricted VAR, Bayesian VAR with unit root priors and reduced rank regression has substantial effects on policy analysis. An additional advantage of the VEC specification is that the cointegration relations provide identification 
restrictions and allow us to distinguish shocks that have either permanent or transitory effects.

As it has not yet been done for fiscal VARs, this paper 1) expands the set of identification strategies with increasingly popular statistical methods and 2) takes into consideration the cointegration properties of the time series. Both extensions - dealing with the nonstationarity of the data, and combining statistical and theoretical information for identification - are expected to increase the accuracy of the results (Phillips 1998, Herwartz \& Lütkepohl 2014).

Quarterly data for the United States are used. The data cover the period 1981Q3 to 2012Q4 and were previously used by Caggiano et al. (2015), as well as Auerbach and Gorodnichenko (2012). Similarly to Caggiano et al. (2015), fiscal policy anticipation effects, or foresight are addressed by including the fiscal news variable proposed by Gambetti (2012). A drawback of using this variable is the relatively short sample. While we recognize that this is one limitation of the analysis, there are advantages in following this approach (see Section 3.1).

The analysis highlights differences between the different VAR specifications used to analyze the effects of fiscal policy. The impulse responses based on the VEC model with mixed normal errors are quite different from those typically obtained from SVAR models, as the latter mostly coincide with theoretical models in the Keynesian tradition. Our results show that a government spending shock has a weak but negative effect on GDP, while the response of taxes is not statistically different from zero even if no restrictions are imposed on taxes. As government revenue does not change, this can be interpreted as a fiscal policy shock financed by a deficit as in Mountford and Uhlig (2009). Also quite surprisingly, a government revenue shock triggers a positive response in both government expenditure and GDP. In line with the interpretation of the spending shock, this can be interpreted as a tax increase to finance government spending, which has a positive impact on GDP. The fiscal multiplier for the horizons $h=1,4,8,12,20$ after the initial shock ranges from -1.27 to -1.61 and achieves its maximum at $h=1$. 
The rest of the paper is organized as follows. Technical details of the empirical method are given in Section 2. Section 3 covers the empirical analysis and Section 4 concludes the paper.

\section{Vector Error Correction (VEC) Model with Non-normal Error Distribution}

Unlike what is typically done in the existing fiscal policy literature, this paper specifies a vector error correction model (VECM) and estimates it to take into account the cointegration properties of the variables. If some or all of the variables are $\mathrm{I}(1)$ and some of the variables are cointegrated, there are advantages in using the VEC representation of the process instead of the vector autoregressive (VAR) representation. Utilizing the cointegration properties of the variables provides identification restrictions, allowing us to distinguish between permanent and transitory shocks.

A reduced form VEC(p) model with a cointegration of rank $r<K$ (deterministic terms omitted for simplicity) is

$$
\Delta \mathbf{y}_{t}=\alpha \boldsymbol{\beta}^{\prime} \mathbf{y}_{t-1}+\boldsymbol{\Gamma}_{1} \Delta \mathbf{y}_{t-1}+\cdots+\boldsymbol{\Gamma}_{p-1} \Delta \mathbf{y}_{t-p+1}+\mathbf{u}_{t}
$$

where $\mathbf{y}_{t}$ is a $K \times 1$ vector of a time series, $\boldsymbol{\alpha}$ is a $K \times r$ matrix of loading coefficients, $\boldsymbol{\beta}$ is a $K \times r$ cointegration matrix, $\Gamma_{j}$ is a $K \times K$ short run coefficient matrix for $j=1, \ldots, p-1$, and $\mathbf{u}_{t} \sim\left(\mathbf{0}, \boldsymbol{\Sigma}_{u}\right)$ is a white noise error vector. The process has the vector moving average (VMA) representation

$$
\mathbf{y}_{t}=\boldsymbol{\Xi} \boldsymbol{\Sigma}_{i=1}^{t} \mathbf{u}_{i}+\boldsymbol{\Xi}_{j}^{*} \boldsymbol{\Sigma}_{j=0}^{\infty} \mathbf{u}_{t-j}+\mathbf{y}_{0}^{*}
$$

where the $\Xi_{j}^{*}$ are absolutely summable and $\mathbf{y}_{0}^{*}$ contains the initial values (see e.g. Lütkepohl 2007, Chapter 9). 
The long-run effects of the shocks are therefore captured by the common trends term

$$
\Xi \Sigma_{i=1}^{t} \mathbf{u}_{i}
$$

and the matrix

$$
\boldsymbol{\Xi}=\boldsymbol{\beta}_{\perp}\left[\alpha_{\perp}^{\prime}\left(I_{K}-\Sigma_{i=1}^{p-1} \Gamma_{i}\right) \beta_{\perp}\right]^{-1} \boldsymbol{\alpha}_{\perp}^{\prime}
$$

has a rank of $K-r$. The symbols $\boldsymbol{\alpha}_{\perp}$ and $\boldsymbol{\beta}_{\perp}$ denote the orthogonal complements of $\boldsymbol{\alpha}$ and $\boldsymbol{\beta}$ respectively. Substituting the relation $\mathbf{u}_{t}=\mathbf{B} \varepsilon_{t}$ in the common trends term (1) gives $\boldsymbol{\Xi B} \Sigma_{1=1}^{t} \varepsilon_{t}$. The term $\boldsymbol{\Xi B}$ contains the long-run effects of the structural shocks and has a rank $K-r$. At most $r$ of the shocks can have transitory effects only, and they are associated with zero columns in the long run matrix $\Xi B$.

To obtain additional information for identification, Lanne and Lütkepohl (2010) assume that the $K$-dimensional error term $\mathbf{u}_{t}$ is a mixture of two serially independent normal random vectors

$$
\mathbf{u}_{t}=\left\{\begin{array}{lll}
\mathbf{e}_{1 t} \sim \mathbf{N}\left(\mathbf{0}, \boldsymbol{\Sigma}_{1}\right) & \text { with } & \text { probability } \\
\mathbf{e}_{2 t} \sim \mathbf{N}\left(\mathbf{0}, \boldsymbol{\Sigma}_{2}\right) & \text { with } & \text { probability } 1-\gamma
\end{array}\right.
$$

where $\mathbf{N}(\mathbf{0}, \boldsymbol{\Sigma})$ denotes a multivariate normal distribution with a mean of $\mathbf{0}$ and a covariance matrix $\Sigma$. In the model $\Sigma_{1}$ and $\boldsymbol{\Sigma}_{2}$ are $(K \times K)$ covariance matrices that are assumed to be distinct, $\gamma$ is the mixture probability, and $0<\gamma<1$, a parameter of the model. Since the term $\gamma$ is only identified if $\boldsymbol{\Sigma}_{1} \neq \boldsymbol{\Sigma}_{2}$, this is assumed to hold. If some parts of $\boldsymbol{\Sigma}_{1}$ and $\boldsymbol{\Sigma}_{2}$ are identical then some components of $\mathbf{u}_{t}$ may be normally distributed. In any case there only needs to be one nonnormal component in $\mathbf{u}_{t}$. The distribution of the reduced form error term now becomes

$$
\mathbf{u}_{t} \sim\left(\mathbf{0}, \gamma \boldsymbol{\Sigma}_{1}+(\mathbf{1}-\gamma) \mathbf{\Sigma}_{2}\right)
$$

The distributional assumption for $\mathbf{u}_{t}$ allows us to define a locally unique $\mathbf{B}$ matrix in the following way. As shown in Appendix A by Lanne and Lütkepohl 
(2010), a diagonal matrix $\boldsymbol{\Psi}=\operatorname{diag}\left(\psi_{1}, \ldots, \psi_{k}\right), \psi_{i}>0(i=1, \ldots, K)$ and a $(K \times K)$ matrix $\mathbf{W}$ exist such that $\boldsymbol{\Sigma}_{1}=\mathbf{W} \mathbf{W}^{\prime}$ and $\boldsymbol{\Sigma}_{2}=\mathbf{W} \mathbf{\Psi} \mathbf{W}^{\prime}$ and $\mathbf{W}$ is locally unique for some ordering of $\psi_{i}$ 's except for a change in the sign of a column, as long as all $\psi_{i}$ 's are distinct. Now we can rewrite the covariance matrix of the reduced form error vector $\mathbf{u}_{t}$ as

$$
\boldsymbol{\Sigma}_{u}=\gamma \mathbf{W} \mathbf{W}^{\prime}+(1-\gamma) \mathbf{W} \boldsymbol{\Psi} \mathbf{W}^{\prime}=\mathbf{W}\left(\gamma \mathbf{I}_{k}+(1-\gamma) \mathbf{\Psi}\right) \mathbf{W}^{\prime}
$$

Given that the structural shocks $\varepsilon_{t} \sim\left(\mathbf{0}, \mathbf{I}_{K}\right)$ are related to the reduced form errors as

$$
\mathbf{u}_{t}=\mathbf{B} \varepsilon_{t}
$$

and

$$
E\left(\mathbf{u}_{t} \mathbf{u}_{t}^{\prime}\right)=\mathbf{\Sigma}_{\mathbf{u}}=\mathbf{B} \boldsymbol{\Sigma}_{\varepsilon} \mathbf{B}^{\prime}=\mathbf{B B}^{\prime}
$$

it follows that a locally unique $\mathbf{B}$ matrix is given by

$$
\mathbf{B}=\mathbf{W}\left(\gamma \mathbf{I}_{n}+(1-\gamma) \boldsymbol{\Psi}\right)^{1 / 2}
$$

This is sufficient for identification.

This choice of $\mathbf{B}$ also means that the orthogonality of shocks is independent of regimes. This can be seen by applying (4) to the covariance matrices as

$$
\begin{array}{llc}
\mathbf{B}^{-1} \boldsymbol{\Sigma}_{u} \mathbf{B}^{-1} & = & \mathbf{I}_{k} \\
\mathbf{B}^{-1} \boldsymbol{\Sigma}_{1} \mathbf{B}^{-1} & = & \left(\gamma \mathbf{I}_{k}+(1-\gamma) \mathbf{\Psi}\right)^{-1} \\
\mathbf{B}^{-1} \boldsymbol{\Sigma}_{2} \mathbf{B}^{-1} & = & \left(\gamma \mathbf{I}_{k}+(1-\gamma) \boldsymbol{\Psi}\right)^{-1} \mathbf{\Psi}
\end{array}
$$

As the equations in (6) are all diagonal matrices, the choice of $\mathbf{B}$ as in (5) yields shocks that are orthogonal in both regimes. The model is estimated by the maximum likelihood (ML) method.

A number of other statistical identification procedures for SVAR models have been proposed in the literature recently, and have already been applied to monetary policy (see e.g. Lanne and Lütkepohl 2014). Rigobon (2003) and Lanne and Lütkepohl (2008) have developed methods based on regimes with different 
covariance structures. Heteroskedasticity may arise as a result of financial crises, for example. These methods further assume that changes in the covariance occur at fixed points during the sample period. This may be a problematic assumption if no such break points are known to exist.

In contrast, both Lanne et al. (2010) and Lütkepohl and Netšunajev (2014) model the volatility shifts as a Markov regime switching process, in which changes in volatility are endogenously determined.

All of these methods are based on either conditional or unconditional heteroskedasticity. More recently Lanne et al. (2015) have introduced a yet more general approach that encompasses most of the methods previously introduced. Similarly to the method employed in this paper, identification in their approach is based on non-Gaussianity of the error terms but more wide-ranging specifications for the error distribution are allowed.

The choice of the identification method based on mixed normality used in this paper is largely dictated by the data. There is no known break in the sample as required by Rigobon (20013) and Lanne and Lütkepohl (2008). On the other hand, modeling volatility regimes as a Markov switching process as in Lanne et al. (2010) is numerically demanding, especially if short time series are used. Finally, Lanne et al. (2015) only discuss a stationary VAR process, the use of which is not feasible given that our data appear cointegrated. Further evidence in support of the specific distributional assumption is presented in Section 3.2. Normality is rejected by formal tests and an investigation of the residuals speaks in favor of a mixed normal specification, which can encompass a wide variety of distributions with the characteristics observed in the residuals. The VEC specification is justified by statistical analysis of the data. 


\section{Empirical Analysis of the Fiscal Multiplier in the US}

\subsection{Data}

In the analysis quarterly US data in a four variable VECM $y_{t}=\left(G_{t}, T_{t}, Y_{t}, \eta_{13}^{g}\right)^{\prime}$ is used, in which $G_{t}$ is $\log$ real government (federal, state, local) expenditure on consumption and investment, $T_{t}$ is log real government receipts of direct and indirect taxes net of transfers to businesses and individuals, and $Y_{t}$ is log real gross domestic product (GDP) in chained 2009 dollars. The variables are constructed using the Bureau of Economic Analysis' NIPA Tables. ${ }^{3}$ These data have been available since 1947Q1 and were previously used by Auerbach and Gorodnichenko (2012), Mountford and Uhlig (2009) and Caggiano et al. (2015), among others.

Fiscal foresight creates problems with structural VAR analysis. If economic agents adjust their behavior based on anticipated future shocks, or news shocks, while standard VARs take into account current and past shocks only, analysis based on these may be misleading. Leeper et al. (2013) show that foresight about changes in future variables leads to non-invertible moving average representations. Instead of the standard (causal) VAR representation, the process has a noncausal representation in this case.

Using data for the United States, Lanne and Saikkonen (2009) provide evidence of noncausality in a VAR model with fiscal foresight. This finding invalidates analyses based on conventional causal VARs, as the errors from a standard VAR cannot be used to reveal the true fiscal shocks precisely.

Even if noncausality is detected, methods for such things as impulse response analysis from noncausal VAR models are unfortunately not yet readily available

\footnotetext{
${ }^{3}$ Government expenditure is the sum of consumption expenditure and gross investment minus the consumption of fixed capital. Government revenue is computed as the difference between current receipts and government social benefits. The implicit GDP deflator is used to transform nominal series into real terms.
} 
(Lanne \& Saikkonen 2013). As the foresight problem arises because the econometrician does not have all the information that economic agents may have, an alternative approach is to solve the inherent missing variable problem by adding variables to the VAR (see Lütkepohl 2014 and the references therein).

To deal with fiscal foresight, we follow Caggiano et al. (2015) who apply the expectations revisions, or news variable approach proposed by Gambetti (2012). A news variable $\eta_{1 J}^{g}$ is constructed from forecast revisions of the growth rate of real government expenditure and added to the VAR. In other words, the VAR is augmented by information about the anticipated fiscal spending shock, which should bring the econometrician's information set closer to that of economic agents. As the forecast revisions used to construct the news variable have been collected by the Survey of Professional Forecasters (SPF) since 1981Q3, the whole sample is restricted to the 1981Q3-2013Q1 period. ${ }^{4}$

As already pointed out by Caggiano et al. (2015), who are the first to use the fiscal news variable, the relatively short sample is one limitation of the analysis. To avoid potential small sample issues, an alternative would be to use Ramey's military news variable (2011b). There are two reasons why the military spending variable does not constitute a solution in this case. According to Ramey (2011b) and Christiano (2013), the military shock variable is a relevant instrument as long as WWII or the Korean War is included. However, during the two wars, fiscal spending was accompanied by considerable increases in taxes and, especially during the Korean War, the increase in spending was permanent. Therefore, the resulting multiplier is not necessarily applicable to a situation in which government spending is financed differently (Ramey 2011b, Christiano 2013). Caggiano et al. (2015) also point out that rationing was in place during WWII, which restrained public spending from increasing further.

Christiano (2013) and Caggiano et al. (2015) conclude, that all these elements are likely to contaminate the computation of the fiscal multiplier based on Ramey's

\footnotetext{
${ }^{4}$ The public expenditure news variable was provided by Giovanni Caggiano. All other variables were constructed by the author.
} 
military spending variable. Moreover, given the limited applicability of Ramey's variable, using it would prevent us from drawing conclusions on the effects of government spending in the current situation, in which fiscal stimulus packages have been financed by debt. We choose to follow Caggiano et al. (2015) because theirs was also the most recent approach to tackling the issue of fiscal foresight.

The cumulated fiscal news variable is constructed by adding up revisions of expectations as follows (Caggiano et al. 2015, Gambetti 2012):

$$
\eta_{1 J}^{g}=\sum_{j=1}^{J}\left(E_{t} g_{t+j}-E_{t-1} g_{t+j}\right)
$$

where $E_{t} g_{t+j}$ is the forecast of the growth rate in real federal government expenditure from period $t+j-1$ to period $t+j$ based on the information available at time $t$. Therefore $E_{t} g_{t+j}-E_{t-1} g_{t+j}$ represents the news that becomes available to private agents between times $t-1$ and $t$ about the growth rate of government expenditure $j$ periods ahead. As the SPF collects forecasts conditional on time $t-1$ up to time $t+3$, to exploit the largest amount of news available, $J=3$ has been selected (Caggiano et al. 2015).

Caggiano et al. (2015) show that residuals typically employed in a standard trivariate VAR are partly predictable by the components of $\eta_{13}^{g}$ and cannot be interpreted as fiscal shocks - the authors claiming that the forecast revisions included in the variable $\eta_{13}^{g}$, which they interpret as a measure of anticipated fiscal shocks, can augment the information content of the VAR system. Therefore, by adding the cumulated fiscal news variable in the VAR, one obtains a shock that is not predictable and can be interpreted as a fiscal shock.

\subsection{Model Setup}

The empirical analysis starts with checking the orders of integration of the four times series, which are depicted in Figure 1. A trend was included in the augmented Dickey-Fuller (ADF) unit root test for all series and autoregressive lags were chosen according to the Akaike information criterion. The tests show that 
Figure 1: Plot of logarithmic time series 1981Q3-2012Q4. G = government expenditure, $\mathrm{T}=$ government revenue, $\mathrm{Y}=\mathrm{GDP}$, news $=$ cumulated fiscal news
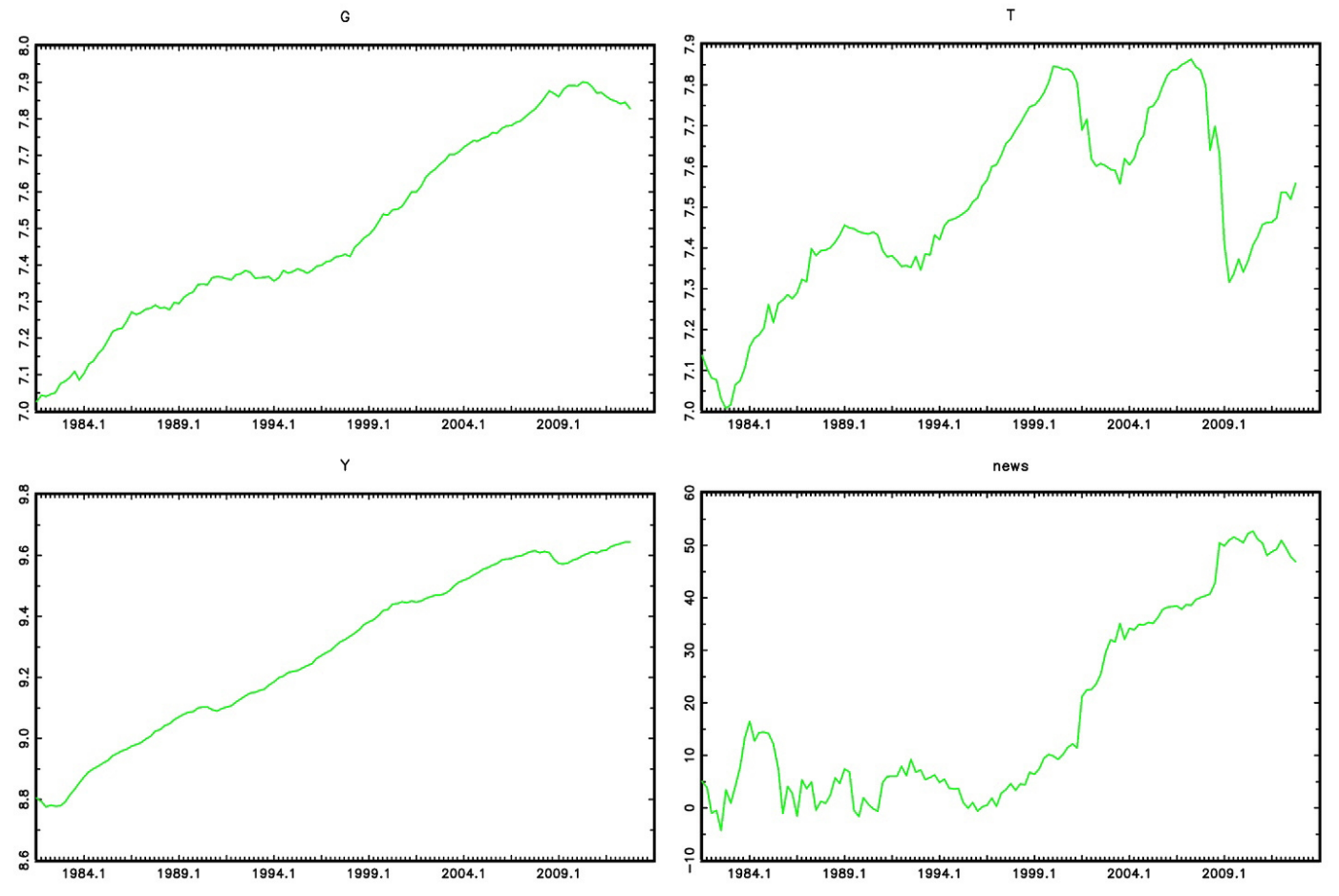

all the variables included in the analysis are $\mathrm{I}(1)$, although $T$ is only at the $5 \%$ significance level, not at the $10 \%$.

The next step is to investigate the cointegration rank of the four dimensional VECM for $y_{t}=\left(G_{t}, T_{t}, Y_{t}, \eta_{13}^{g}\right)^{\prime}$. This requires determining the number of lagged differences in the system first. Here we use the fact that if a $\operatorname{VAR}(\mathrm{p})$ process contains cointegrated variables, the process has a $\operatorname{VEC}(\mathrm{p}-1)$ representation. In other words the order $p$ is chosen so that no residual autocorrelation is left in the corresponding VAR model. For a reduced form Gaussian VAR, AIC, HQ and BIC select $\operatorname{VAR}(6), \operatorname{VAR}(2)$ and $\operatorname{VAR}(1)$ models, respectively. According to the adjusted portmanteau test there is autocorrelation left in the $\operatorname{VAR}(1)$ model $(p$ value $<0.001)$, while a $p$-value of 0.082 for $\operatorname{VAR}(2)$ suggests that a second order model is sufficient.

Table 1 reports the results of the Johansen Trace test with an unrestricted constant. The cointegration rank $r=0$ is rejected at all significance levels, while 
Table 1: Cointegration tests

\begin{tabular}{|c|c|c|c|c|c|}
\hline \multicolumn{6}{|l|}{ Johansen Trace test } \\
\hline \multirow[t]{2}{*}{ Included lags (levels) } & \multirow[t]{2}{*}{$\overline{\overline{\mathbf{H}_{0}}}$} & \multirow[t]{2}{*}{ Test value } & \multicolumn{2}{|c|}{ Critical values } & \multirow[t]{2}{*}{$p$-value } \\
\hline & & & $10 \%$ & $5 \%$ & \\
\hline \multirow[t]{4}{*}{2} & 0 & 90.17 & 50.50 & 53.94 & 0.00 \\
\hline & 1 & 32.31 & 32.25 & 35.07 & 0.099 \\
\hline & 2 & 15.40 & 17.98 & 20.16 & 0.21 \\
\hline & $\overline{3}$ & 2.51 & 7.60 & 9.14 & 0.68 \\
\hline \multicolumn{6}{|c|}{ Saikkonen and Lütkepohl test } \\
\hline \multirow{2}{*}{ Included lags (levels) } & \multirow[t]{2}{*}{ 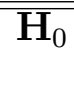 } & \multirow[t]{2}{*}{ Test value } & \multicolumn{2}{|c|}{ Critical values } & \multirow[t]{2}{*}{$\bar{p} p$-value } \\
\hline & & & $10 \%$ & $5 \%$ & \\
\hline \multirow[t]{4}{*}{2} & 0 & 53.97 & 37.04 & 40.07 & 0.00 \\
\hline & 1 & 17.85 & 21.76 & 24.16 & 0.26 \\
\hline & 2 & 4.09 & 10.47 & 12.26 & 0.70 \\
\hline & 3 & 2.49 & 2.98 & 4.13 & 0.14 \\
\hline
\end{tabular}

$r=1$ clearly cannot be rejected at the $5 \%$ level and is barely rejected at the 10 \% level. ${ }^{5}$ The Saikkonen and Lütkepohl (2000) cointegration test - also reported in Table 1 - provides further support for $r=1 .^{6}$

To conclude the initial analysis, diagnostic tests have been performed to assess the suitability of the $\operatorname{VEC}(1)$ model with $r=1$. There appears to be no remaining autocorrelation (adjusted portmanteau test $p$-value 0.18). There is however evidence of non-normality in the errors, as is evident from the quantile-quantile (QQ) plots of the model residuals. ${ }^{7}$ Normality is also rejected by formal normality tests, of which the Doornik and Hansen test for joint normality yields a $p$-value of $<0.001$, and the $p$-values of univariate Jarque-Bera tests are reported in Table 2.

Table 2: Summary Statistics

\begin{tabular}{|l|l|l|l|l|}
\hline & Skewness & Kurtosis & Jarque-Bera & $p$-value \\
\hline Government Expenditure & -0.6092 & 4.0185 & 12.7127 & 0.0017 \\
Government Revenue & -1.1325 & 5.8725 & 67.4635 & 0.0000 \\
GDP & -0.4198 & 3.6481 & 5.6724 & 0.0586 \\
Fiscal News & 0.1002 & 6.0327 & 46.5728 & 0.0000 \\
\hline
\end{tabular}

\footnotetext{
${ }^{5}$ The low power of the test has meant that the rank is often selected according to the $10 \%$ significance level (Brüggemann \&Lütkepohl 2005).

${ }^{6}$ As a robustness check, the mixture VECM was estimated with $r=2$ as well and the test results are qualitatively the same as those reported in Section 3.3.

${ }^{7}$ To save space, the QQ plots are not reported here, but are available from the author upon request.
} 
The QQ plots illustrate that most discrepancies from a normal distribution occur at the tails. The curved pattern of the QQ plots for government expenditure, government revenue and GDP can arise because of a left skewed data distribution compared to the normal, while the QQ plot of the fiscal news variable shows heavy tails at both ends of the distribution. These observations are confirmed by the figures in Table 2. In fact, government expenditure, government revenue and GDP feature negative/left skewness, whereas the fiscal news variable is positively/right skewed. Moreover, the kurtosis shows values greater than 3 for all variables, indicating heavier tails and higher peaks than in a normal distribution.

Heavy tails and skewness are typical features of financial time series such as asset returns. To accommodate these characteristics, mixtures of normal distributions have been used to analyze financial data. According to Tsay (2005), studies of stock returns have started to use a mixed normal distribution because it can capture the skewness and excess kurtosis of the time series. By using a mixture distribution, one can obtain densities with higher peaks and heavier tails than in the normal distribution. Kon (1984), for example used a mixed normal model to explain the observed significant kurtosis and significant positive skewness in the distribution of daily rates of stock returns. Overall, because of their flexibility, mixture models are increasingly exploited to model unknown distributions (McLachlan \& Peel 2000).

In the present VECM setup with mixed normal errors, normal distribution is obtained if $\boldsymbol{\Sigma}_{1}=\boldsymbol{\Sigma}_{2}$ in (2). Therefore the normality tests may be seen as a test of $H_{0}: \Sigma_{1}=\Sigma_{2}$, the rejection of which supports the assumption that $\boldsymbol{\Sigma}_{1} \neq \boldsymbol{\Sigma}_{2}$, and hence a mixed normal error distribution (Lanne and Lütkepohl 2010).

Given these properties of the data, explicitly modeling the error distribution as a mixed normal distribution is well grounded. The considerable advantage of the specific distributional assumption is that it yields additional databased information, which allows us to identify the model without restrictions. As a result, identification restrictions derived from other sources become over-identifying and 
their validity can be statistically tested. ${ }^{8}$

\subsection{Estimation Results and Structural Identification}

The estimation of the mixture VEC model proceeds in two steps (Lanne and Lütkepohl 2010). As the cointegration relations are not known beforehand, they are first estimated with the Johansen reduced rank regression, which yields $\boldsymbol{\beta}=$ $(1,-0.447,-0.171,-0.007) .^{9}$ In the second step the log-likelihood function is maximized with respect to the other parameters, conditional on the estimated cointegation relations. ${ }^{10}$

In the ML estimation, VECM coefficients from a linear model are used as starting values to estimate the parameters of an unrestricted VEC model with a mixed normal distribution. The estimation results of the unrestricted model appear in the left column of Table $3 .^{11}$

The model has been identified if the $\psi_{i}^{\prime}$ s are distinct. As shown in Table 3, the estimation results are quite precise and the $\psi_{i}^{\prime}$ s yield approximate values of 0.11 , $0.26,0.06$ and 0.76 , while the mixture probability $\gamma$ is estimated to be 0.24 .

Statistical identification delivers orthogonal shocks but their labeling has to be based on outside information (Lanne et al. 2015, Lütkepohl \& Netšunajev 2014). One option is to test the validity of a recursive identification scheme that has been used before. If the previously used restrictions cannot be rejected, the recursive structure provides a straightforward interpretation of the resulting

\footnotetext{
${ }^{8}$ We follow previous literature and test normality in a first step and, conditional on rejecting it, test standard SVAR identification schemes in a second step. This is the common procedure in the literature employing statistical identification in SVAR models because a joint test would be nonstandard and probably difficult to perform in practice. We thank the editor for pointing out this potential problem.

${ }^{9}$ The first step computations were performed with JMulTi.

${ }^{10}$ These computations were done with GAUSS programs using the CMLMT library. To avoid numerical problems in estimation, the fiscal news variable is scaled to match the magnitude of the other variables.

${ }^{11}$ The rest of the parameter estimates will be provided upon request.
} 
Table 3: Estimation results of the VECM with mixture distribution, restricted and unrestricted B matrix. Standard errors in parenthesis.

\begin{tabular}{lccc}
\hline \hline $\mathbf{y}_{t}=\left(G_{t,}, T_{t}, Y_{t}, \eta_{13}^{g}\right)^{\prime}$ & & \\
\hline \hline Parameter & Unrestricted B & Restricted B & Restricted B and $\Xi \mathbf{B}$ \\
$\hat{\gamma}$ & $0.2391(0.0862)$ & $0.1241(0.0251)$ & $0.2318(0.0645)$ \\
$\hat{\psi}_{1}$ & $0.1149(0.0417)$ & $0.1638(0.0688)$ & $0.0968(0.0371)$ \\
$\hat{\psi}_{2}$ & $0.2554(0.1097)$ & $0.0618(0.0273)$ & $0.0810(0.0296)$ \\
$\hat{\psi}_{3}$ & $0.0613(0.0242)$ & $0.1415(0.0578)$ & $0.1893(0.0830)$ \\
$\hat{\psi}_{4}$ & $0.7617(0.3066)$ & $0.7248(0.0001)$ & $0.7483(0.2768)$ \\
$\max l_{T}(\theta)$ & 1620.56 & 1605.15 & 1618.64 \\
$\mathrm{LR}$ & & 30.82 & 3.84 \\
$p$-value & & $2.743 \times 10^{-5}$ & 0.698 \\
\hline
\end{tabular}

impulse response functions. Statistical testing of a recursive identification scheme is therefore an important part of the economic interpretation of the results.

To this end, another VEC model is estimated in which lower triangularity is imposed on the $\mathbf{B}$ matrix as in Caggiano et al. $(2015)^{12}$. In estimating the restricted model, the ML estimates of the unrestricted model are used as starting values. In both cases, their determinants are bounded away from zero to ensure nonsingularity of the covariance matrices. The diagonal elements of the $\boldsymbol{\Psi}$ matrix are also bounded away from zero, as required.

The results of the key parameters are reported in the middle column of Table 3 together with the outcome of the likelihood ratio test ${ }^{13}$. The LR test has the asymptotic $\chi^{2}$-distribution with 6 degrees of freedom given by the number of restrictions. The recursive structure is clearly rejected ( $p$-value $<0.001$ ) and hence is not helpful in labelling the shocks.

The VECM specification allows another option based on long run relations between the variables, as shown in Lütkepohl (2007, Chapter 9). Suppose the cointegration rank is known to be $r$. Then, as in Section 2, there are at most $r$ transitory shocks, $\varepsilon_{t}^{r}$ and at least $K-r$ permanent shocks, $\varepsilon_{t}^{p}$. Arranging them

\footnotetext{
${ }^{12}$ In the present mixture model this is done in practice by restricting the $\mathbf{W}$ matrix in $\mathbf{B}=$ $\mathbf{W}\left(\gamma \mathbf{I}_{n}+(1-\gamma) \mathbf{\Psi}\right)^{1 / 2}$ to be lower triangular.

${ }^{13}$ The rest of the results are available upon request.
} 
such that $\varepsilon_{t}^{\prime}=\left(\varepsilon_{t}^{p \prime}, \varepsilon_{t}^{r \prime}\right)$, it follows that $\boldsymbol{\Xi B}=\left[\boldsymbol{\Phi}_{K \times(K-r)}: \mathbf{0}_{K \times r}\right]$ where $\boldsymbol{\Phi}_{K \times(K-r)}$ is an $K \times(K-r)$ matrix. In a VEC model with $r<K$, all shocks can in principle be permanent shocks and $\boldsymbol{\Xi B}$ may not have zero columns even if it has reduced rank.

In Section 3.2., $r=1$ was found for the data to hand. This translates into the following set of long run restrictions ${ }^{14}$

$$
\mathbf{\Xi B}=\left[\begin{array}{llll}
* & * & * & 0 \\
* & * & * & 0 \\
* & * & * & 0 \\
* & * & * & 0
\end{array}\right]
$$

which can also be tested using a LR-test. ${ }^{15}$ Therefore another restricted VEC model with mixed normal errors is estimated. The following matrix of impact effects is assumed

$$
\mathbf{B}=\left[\begin{array}{llll}
* & 0 & 0 & * \\
* & * & 0 & * \\
* & * & * & * \\
* & * & * & *
\end{array}\right]
$$

in addition to the long run restriction in (7). In other words, the often used recursive structure for the key variables $\mathbf{y}_{t}=\left(G_{t}, T_{t}, Y_{t}\right)$ is imposed as well. This implies that government expenditure does not respond contemporaneously to shocks to other variables, while government revenue does not react contemporaneously to output shocks.

Note that the restrictions imposed here (7 and 8) differ from those required for identification in a standard VECM framework (see e.g. Lütkepohl 2007, Chapter 9 ). Because the matrix $\boldsymbol{\Xi B}$ has a reduced rank of $K-r$, each column of zeros stands for $K-r$ independent restrictions only. In other words the $r$ transitory shocks represent $r(K-r)$ independent restrictions, i.e. 3 in the present case. As just-identification in the standard VECM requires a total of $\frac{K(K-1)}{2}$ restrictions,

\footnotetext{
${ }^{14}$ Again the asterisks denote unrestricted elements and zeros indicate the elements that are restricted to be zero.

${ }^{15}$ The assumption that government spending, revenue and output shocks have permanent effects is in line with the literature using the same data (see e.g. Mountford \& Uhlig 2009, and the results from both linear and nonlinear models by Auerbach \& Gorodnichenko 2012).
} 
additional restrictions based on theoretical considerations are needed. To identify both transitory and permanent shocks, it is not sufficient to impose arbitrary restrictions on $\mathbf{B}$ and $\boldsymbol{\Xi B}$, however. The advantage of the VEC specification in the standard setting is that the $r(K-r)$ restrictions are based on the cointegration rank, which can be determined by statistical tests.

In the current framework, assuming that structural shocks are in fact identified by the mixed normality of errors, any restrictions become over-identifying and can be statistically tested. Testing the exclusion restrictions in (8) is of interest because they are commonly assumed to obtain just-identification with standard three variable VARs. Obviously, the three restrictions in (8) alone are not enough to identify a four variable VAR.

The estimation results of the second restricted VEC model appear in the right column of Table $3 .{ }^{16}$ The $p$-value of the LR test (0.698) based on the $\chi^{2}(6)$ distribution indicates that restrictions (7) and (8) are well supported by the data (see the right column of Table 3).

Finally, an examination of the standard errors suggests that some of the $\psi_{i}^{\prime}$ s may not be distinct. This means that the $\mathbf{B}$ matrix may not be unique. The nonuniqueness of $\mathbf{B}$ may imply that the actual number of degrees of freedom of the $\chi^{2}$-distribution in the LR-test is less than 6 (see Lütkepohl and Velinov 2014). Given the rejection of the first restricted model at 6 degrees of freedom, the same test statistic leads to rejection with fewer degrees of freedom as well. Therefore, even though the $\mathbf{B}$ matrix may not be unique, by assuming mixed normality of the errors, the restrictions imposed are sufficient to reject the recursive identification scheme. On the other hand, given the small value of the LR test statistic related to the second restricted model, even with less than 6 degrees of freedom there is still no strong evidence against the restrictions imposed.

\footnotetext{
${ }^{16}$ The rest of the results are available upon request.
} 


\subsection{Impulse Response Analysis}

Given the previous results, and assuming that the $\psi_{i}$ 's are distinct and the model is in fact fully identified, we compute impulse responses based on the restricted mixture VEC model, which imposes both contemporaneous and long-run restrictions (7 and 8) not rejected by the data. We report the $90 \%$ Hall's percentile confidence bands, which are obtained from 1000 replications of bootstrap impulse responses. Following Herwartz and Lütkepohl (2014), to ensure that only bootstrap replications around the parameter space of the original estimation step are considered, bootstrap parameter estimates of $\mathbf{c}, \mathbf{W}, \boldsymbol{\alpha}$ and $\boldsymbol{\Gamma}_{1}$ are determined conditionally on the initially estimated $\boldsymbol{\Psi}$ and $\gamma$. Bootstrap estimates are obtained by nonlinear optimization of the log-likelihood with ML estimates as starting values.

Figure 2: Impulse response functions with 90\% Hall's percentile confidence bands of the restricted VEC model with mixed normal errors.
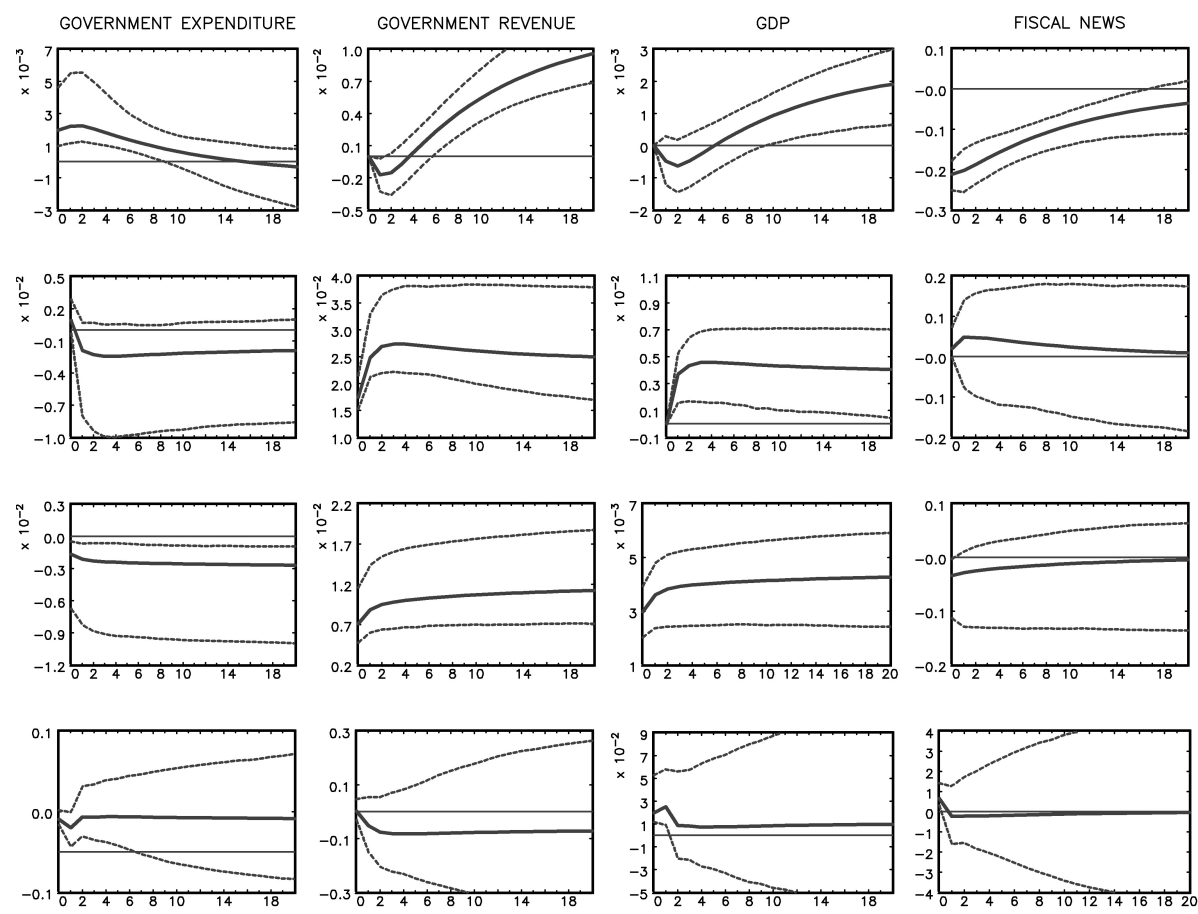

The impulse responses are shown in Figure 2. Each column contains the responses of all variables to one shock, the size of each shock being set to unity. In this case the long and short run restrictions provide interpretation. As the 
impulse responses are computed by restricting the impact effects as in (8), the following contemporaneous effects are ruled out: a government revenue shock has no contemporaneous impact on government expenditure $\left(G_{t}\right)$, and an output shock cannot have a contemporaneous effect on government expenditure $\left(G_{t}\right)$ and revenue $\left(T_{t}\right)$. From the long run restriction (7) we also know that the effect of the last shock - fiscal news $\left(\eta_{13}^{g}\right)$ - is transitory. These permit us to uniquely label the shocks as a government spending, government revenue, output and fiscal news shock. In other words they appear in the same order as the variables in the vector $y_{t}=\left(G_{t}, T_{t}, Y_{t}, \eta_{13}^{g}\right)^{\prime}$.

The first column of Figure 2 depicts impulse responses to a positive government spending shock. Interestingly, the response of output is negative although very weak, while the response of taxes is not statistically different from zero, even if no restrictions on taxes are imposed. As government revenue does not change, this can be interpreted as a fiscal policy shock financed by a deficit as in Mountford and Uhlig (2009). From a practical point of view, this is of great interest since fiscal stimulus packages are mostly financed by deficits.

The second column reports impulse responses to a positive government revenue shock. The impact response of government expenditure is restricted to zero, but it becomes positive and significant after 6 quarters, and so follows the shape of GDP. In other words, surprisingly, a government revenue shock is found to trigger a positive response in both government expenditure and GDP. In line with the interpretation of the spending shock, one could interpret government spending financed by a tax increase as having a positive impact on GDP. In the literature a positive tax shock is typically found to have a negative effect on output (see e.g. Ramey 2011a, Favero \& Giavazzi 2012, Mountford \& Uhlig 2009, Auerbach \& Gorodnichenko 2012). For example, in the linear framework of Auerbach and Gorodnichenko (2012), output responds negatively and government spending positively to a positive tax shock, while Mountford and Uhlig (2009) report a negative impact on both output and spending. According to the latter 
authors their finding is also intuitive. To investigate what happens to the response of government spending to a tax shock at longer horizons, we computed impulse responses for such horizons as well. The response of government spending does not seem to stabilize.

The third column displays impulse responses to a positive output shock. Although the impact response of government revenue is restricted to zero here, the output shock behaves like a business cycle shock in Mountford and Uhlig (2009) in that both output and government revenue increase, whereas the response of government expenditure is not countercyclical, also increasing although with a lag. The reason given by Mountford and Uhlig (2009) also applies here, namely the government expenditure variable is defined as consumption plus investment but does not include transfer payments, which automatically vary counter cyclically.

Finally, the last column shows impulse responses to a positive fiscal news shock, which Caggiano et al. (2015) interpret as an anticipated fiscal expenditure shock. The shapes of the impulse responses are similar to Caggiano et al.'s (2015) but there are differences in the impact effects. This is not unexpected given their identification strategy, which imposes zero impact effects of the fiscal news shock on all variables. When the responses to the fiscal news shock are left unrestricted in the mixture VEC model, we see that the impact responses of government expenditure and output are negative but increasing, while the government revenue reacts positively at first and then starts to decrease. The response of the news shock itself is very short-lived. Of these, the responses of government revenue and output are insignificant, however. Apparently, the breadth of the confidence bands reflects the fact there is great uncertainty around the behavior of the cumulated fiscal news variable, which is constructed by adding up forecast revisions of the growth rate of real government expenditure.

Fiscal multipliers are computed according to the usual practice in the literature (see e.g. Auerbach \& Gorodnichenko 2012, Caggiano et al. 2015, Ramey and Zubairy 2013, Mountford \& Uhlig 2009). Specifically, impact multipliers are 
calculated as the response of output at a given horizon divided by the initial fiscal shock. As the log of variables is used in estimation, we scale the IRFs by the sample average of the output to government spending ratio, $Y / G$ (taken in levels) to convert percentage changes into dollar changes. Impact multipliers are computed for the $h=1,4,8,12,20$ horizons. The multiplier ranges from -1.27 to -1.61 and achieves its maximum at $h=1$. As already pointed out, these results rest on the assumption that the mixture VEC model is fully identified.

A comparison with previous empirical studies reveals that the effects of fiscal policy obtained from SVARs are typically of the opposite sign, in accordance with theoretical models in the Keynesian tradition (e.g. Blanchard \& Perotti 2002, Ramey 2011b, Favero \& Giavazzi 2012). There is however a lot of variation in the size of the multiplier, both within and across studies (see Ramey 2011a and references therein).

Similarities also exist. Perotti (2005) finds evidence of large differences in the effects of fiscal policy in the pre- and post-1980 periods. His results for the whole US sample (1960Q1-2001Q4) are similar to those obtained by others using the same sample, whereas a negative spending multiplier emerges for the post-1980 period. He concludes that there has been a drastic reduction in the effects of government spending shocks on GDP since 1980. His results are therefore in line with the ones obtained in this paper, which also considers the post-1980 period.

Mountford and Uhlig (2009) analyze a government spending shock financed by a deficit by not allowing taxes to change for 4 quarters. They find that deficit spending only stimulates the economy weakly on impact and has a negative effect on output in the long run. Their basic government spending shock resembles the deficit spending shock in that although no restrictions on government revenue are imposed, it does not change significantly. Since the same result is obtained here, we interpret our government spending shock as deficit financed.

Negative fiscal multipliers also emerge in studies using nonlinear model specifications, for example during periods of high public debt (Ilzetzki et al. 2013), and 
during expansions in the post-1980 period (Auerbach \& Gorodnichenko 2012).

\section{Conclusions}

In the fiscal policy literature using structural vector autoregressions (SVARs), fiscal policy shocks are identified in several ways. Fiscal multipliers, i.e. estimates of the impact of fiscal stimulus on output, are then defined either as the peak of the impulse response or as an accumulated response. As is well known, the VAR identification strategy matters for the impulse responses, and hence may be one reason for the differing results.

Moreover, as the usual practice in the literature is to use the log of variables, the estimated elasticities are converted to dollar equivalents with an ex post conversion factor, a practice that has also been criticized (Ramey \& Zubairy 2014). Using log levels of variables such as real GDP, government revenue and expenditure also introduces another potential source of uncertainty in the analysis, namely nonstationarity. Phillips (1998) demonstrates that impulse responses are not consistently estimated in the SVARs with variables in levels in the case of unit roots, whereas the vector error correction (VEC) specification significantly improves them even for short horizons. Phillips (1998) found that differential treatment of nonstationarity in various models has substantial effects on policy analysis.

This paper contributes to the existing fiscal policy literature in two ways. First, unlike any of the studies using VARs - linear and non-linear - the vector error correction (VEC) model used in this paper takes into account the cointegration properties of the variables as well. Second, statistical properties of the data are exploited to identify the model, and to test the validity of two popular identification strategies in the fiscal VAR literature.

As proposed by Lanne and Lütkepohl (2010), the non-normality found in the VAR residuals is explicitly modelled, which yields additional data based information. In the Lanne and Lütkepohl (2010) method a mixed normal error dis- 
tribution is used because of its suitability for the features often found in the residuals. Any restrictions from other sources used for identification then become over-identifying and can be statistically tested.

The test results indicate that the commonly used recursive structure for all four variables is too restrictive from a statistical point of view. However, a long run restriction together with a recursive structure for the key variables government expenditure $\left(G_{t}\right)$ government revenue $\left(T_{t}\right)$ and GDP $\left(Y_{t}\right)$ is not rejected by the data. As Caggiano et al. (2015) point out, ordering the fiscal news variable last in a recursive model may be seen as inconsistent with expectational effects.

In the next step, fiscal policy shocks are analyzed using a model with restrictions not rejected by statistical tests. The resulting impulse responses are quite different from those typically obtained from SVAR models. The latter mostly coincide with theoretical models in the Keynesian tradition. According to our results, government spending shock has a weak but negative effect on GDP, while the response of taxes is not statistically different from zero even if no restrictions are imposed on taxes. As government revenue does not change, this can be interpreted as a fiscal policy shock financed by a deficit as in Mountford and Uhlig (2009). Also quite surprisingly, a government revenue shock triggers a positive response in both government expenditure and GDP. In line with the interpretation of the spending shock, this can be interpreted as a tax raise to finance government spending, which has a positive impact on GDP. The fiscal multiplier for horizons $h=1,4,8,12,20$ after the initial shock ranges from -1.27 to -1.61 and achieves its maximum at $h=1$.

\section{Acknowledgements}

The author would like to thank Markku Lanne and Pentti Saikkonen for comments and Giovanni Caggiano for comments and for sharing the data on the fiscal news variable. Financial support from the Eino Jutikkala Fund is gratefully acknowledged. 


\section{References}

[1] Auerbach A.J., \& Gorodnichenko Y. (2012). Measuring Output Responses to Fiscal Policy. American Economic Journal: Economic Policy 4(2): 1-27.

[2] Blanchard O., \& Perotti R. (2002). An Empirical Characterization of the Dynamic Effects of Changes in Government Spending and Taxes on Output. Quarterly Journal of Economics 117(4):1329-68.

[3] Caggiano, G., Castelnuovo, E., Colombo, V., \& Nodari, G. (2015). Estimating Fiscal Multipliers: News From a Nonlinear World!. The Economic Journal 125(584): $746-776$.

[4] Caldara D., \& Kamps C. (2008). What Are the Effects of Fiscal Policy Shocks? A VAR-based Comparative Analysis. European Central Bank Working Paper 87\%.

[5] Christiano L.J. (2013). Comment on Giavazzi and McMahon, 'The Household Effects of Government Spending', in Alberto Alesina and Francesco Giavazzi (Eds.): Fiscal Policy After the Crisis, NBER, University of Chicago Pres, 141-149.

[6] Favero, C., \& Giavazzi, F. (2012). Measuring tax multipliers: The narrative method in fiscal VARs. American Economic Journal: Economic Policy 4(2): 69-94

[7] Gambetti L. (2012). Fiscal Foresight, Forecast Revisions and the Effects of Government Spending in the Open Economy. Universitat Autonoma de Barcelona, mimeo.

[8] Herwartz H., \& Lütkepohl H. (2014). Structural Vector Autoregressions with Markov Switching: Combining Conventional with Statistical Identification of Shocks. Journal of Econometrics 183: 104-116. 
[9] Ilzetzki E., Mendoza E.G., Végh C.A. (2013). How Big (Small?) Are Fiscal Multipliers? Journal of Monetary Economics 60: 239-254.

[10] Kon S.J. (1984). Models of Stock Returns - a comparison. The Journal of Finance 39(1): 147-165.

[11] Lanne M., \& Lütkepohl H. (2008). Identifying Monetary Policy Shocks via Changes in Volatility. Journal of Money, Credit and Banking 40: 1131-1149.

[12] Lanne M., \& Lütkepohl H. (2010). Structural Vector Autoregressions With non-normal Residuals. Journal of Business 83 Economic Statistics 28(1):159168.

[13] Lanne, M. \& Lütkepohl, H. (2014). A Statistical Comparison of Alternative Identification Schemes for Monetary Policy Shocks. Contributions to Mathematics, Statistics, Econometrics, and Finance: Essays is Honour of Professor Seppo Pynnönen.

[14] Lanne M., Lütkepohl H., \& Maciejowska K. (2010) Structural Vector autoregressions with Markov Switching. Journal of Economic Dynamics and Control 34: 121-131.

[15] Lanne M., Meitz M., \& Saikkonen P. (2015). Identification and Estimation of Non-Gaussian Structural Vector Autoregressions. CREATES Research Paper No. 2015-16. School of Economics and Management, University of Aarhus.

[16] Lanne M., \& Saikkonen P. (2009). Noncausal Vector Autoregression. Bank of Finland Research Discussion Papers 18.

[17] Lanne M., \& Saikkonen P. (2013). Noncausal Vector Autoregression. Econometric Theory 29:447-481.

[18] Leeper E.M., Walker T.B.,\& Yang S.-C. S. (2013). Fiscal Foresight and Information Flows. Econometrica 81(3): 1115-1145. 
[19] Lütkepohl H. (2007). New Introduction to Multiple Time Series Analysis, Springer-Verlag, Berlin.

[20] Lütkepohl H. (2014). Fundamental Problems with Nonfundamental Shocks. In: Haldrup N., Meitz M. and Saikkonen P. ed. Essays in Nonlinear Time Series Econometrics, Oxford University Press, pp. 198-214.

[21] Lütkepohl H. \& Netšunajev A. (2014). Disentangling Demand and Supply Shocks in the Crude Oil Market: How to Check Sign Restrictions in Structural VARs. Journal of Applied Econometrics. 29(3):479-496.

[22] Lütkepohl H. \& Velinov A. (2014). Structural Vector Autoregressions: Checking Identifying Long-run Restrictions vie Heteroskedasticity. Journal of Economic Surveys 2014.

[23] McLachlan G. \& Peel D. (2000). Finite Mixture Models. NY: John Wiley \& Sons.

[24] Mountford A., \& Uhlig H. (2009). What Are the Effects of Fiscal Policy Shocks? Journal of Applied Econometrics 24: 960-992.

[25] Owyang M. T., Ramey V. A. \& Zubairy S. (2013). Are government spending multipliers greater during periods of slack? Evidence from 20th century historical data. The American Economic Review 103(3): 129-134.

[26] Perotti R. (2005). Estimating the Effects of Fiscal Policy in OECD Countries. CEPR Discussion Paper 4842.

[27] Phillips P.C.B (1998). Impulse Response and Forecast Error Variance Asymptotics in Nonstationary VARs. Journal of Econometrics 83: 21-56.

[28] Ramey V.A. (2011a). Can Government Purchases Stimulate the Economy? Journal of Economic Literature 49(3): 673-685.

[29] Ramey V.A. (2011b). Identifying Government Spending Shocks: It's All in the Timing. Quarterly Journal of Economics 126(1):1-50. 
[30] Ramey V.A., \& Shapiro M.D. (1998). Costly Capital Reallocation and the Effects of Government Spending. Carnegie-Rochester Conference on Public Policy 48: 145-94.

[31] Ramey V. A. \& Zubairy S. (2014). Government spending multipliers in good times and in bad: evidence from US historical data. NBER Working Paper 20719.

[32] Saikkonen P. \& Lütkepohl H. (2000). Testing for the Cointegrating Rank of a VAR process with an intercept. Econometric Theory 16:373-406.

[33] Sims C. (1980). Macroeconomics and Reality. Econometrica 48(1):1-48.

[34] Tsay R.S. (2005). Analysis of Financial Time Series. Wiley Series in Probability and Statistics.

[35] Uhlig H. (2005). What Are the Effects of Monetary Policy? Results from an Agnostic Identification Procedure. Journal of Monetary Economics 52:381419. 